\title{
Founding Editorial: Higher Level Brain Function
}

\author{
Michael Posner \\ Principal Editor, Higher Level Brain Function
}

Received February 12, 2002; Accepted February 13, 2002; Published March 15, 2002

KEY WORDS: cognition, brain lesions, genetics, pharmacology, rehabilitation

DOMAINS: higher level brain function

With the rapid growth of Affective, Cognitive, Developmental, and Social Neuroscience, the domain of Higher Level Brain Function has become of central importance to understanding the human brain. In this Domain we welcome papers using neuroimaging, genetics, pharmacology, and other methods in studies both directly involving the human brain as well as nonhuman animals. These studies may elucidate how the brain relates to thoughts, feelings, and complex behaviour.

The Higher Level Brain Function Domain will be closely coordinated with the Cognition and other related Domains to ensure that all appropriate submissions are handled rapidly and effectively. As with other Domains, we hope to ensure that the Higher Level Brain Function Domain is a rapid communication environment for papers that have been thoroughly peer reviewed. While not all papers can be published, we would like to be prompt, clear, and helpful in dealing with each submission. We have a large and distinguished Editorial team working on this Domain that represents a range of research interests. We hope that this is reflected in the submissions that we receive.

This article should be referenced as follows:

Posner, M. (2002) Founding editorial: Higher Level Brain Function. TheScientificWorldJOURNAL 2, 738. 

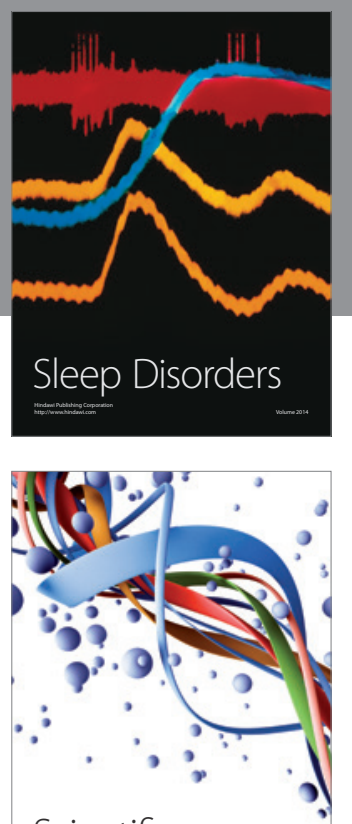

Scientifica
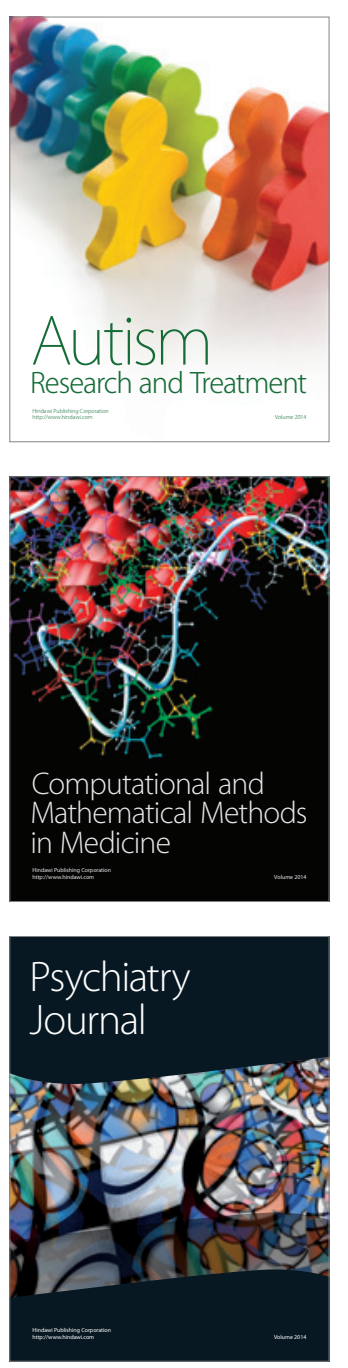
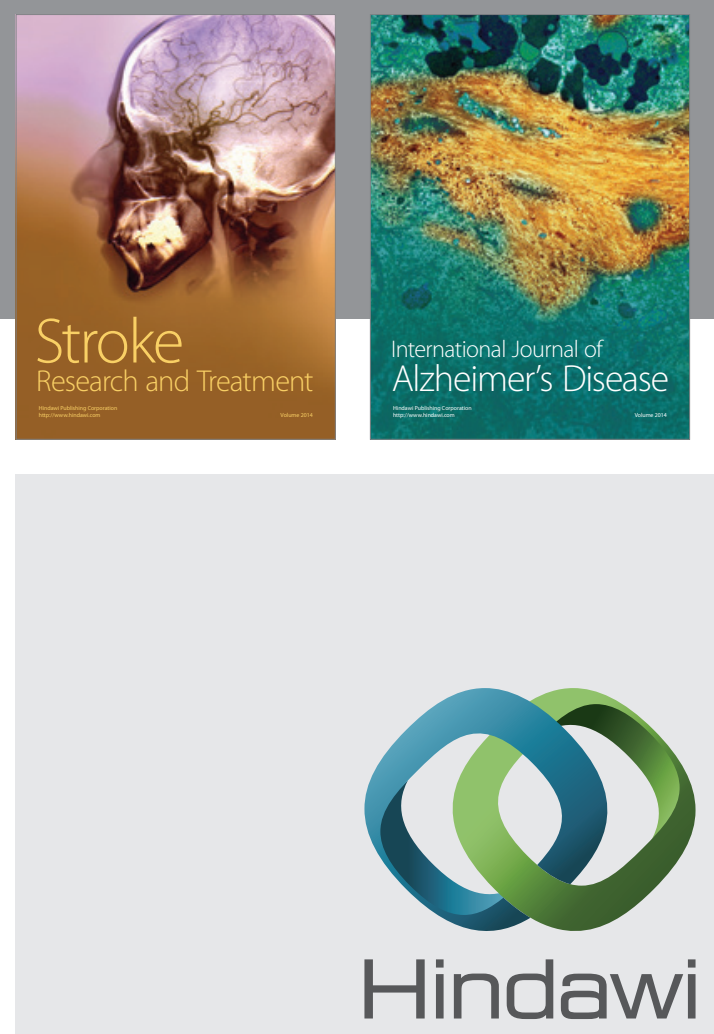

Submit your manuscripts at

http://www.hindawi.com
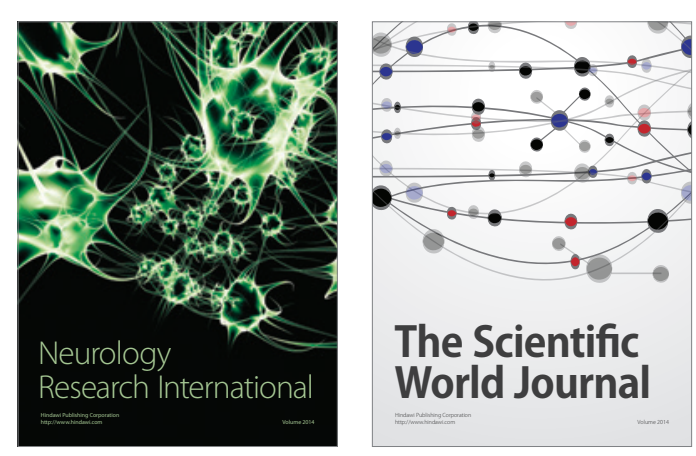

The Scientific World Journal

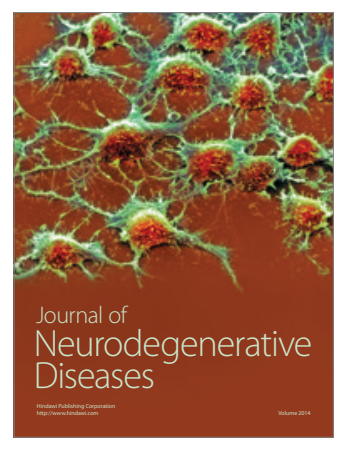

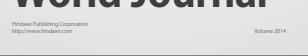

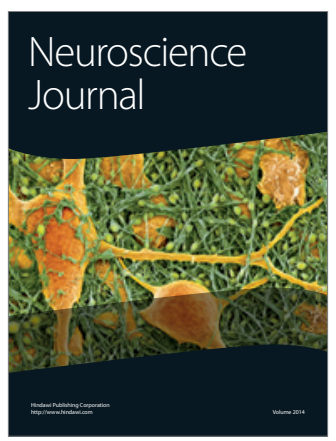

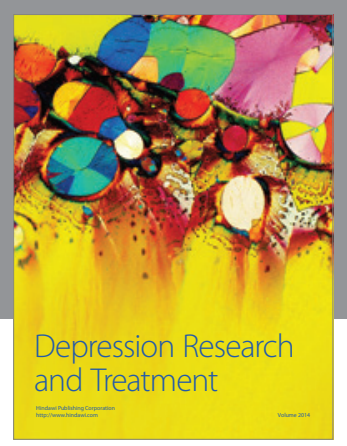
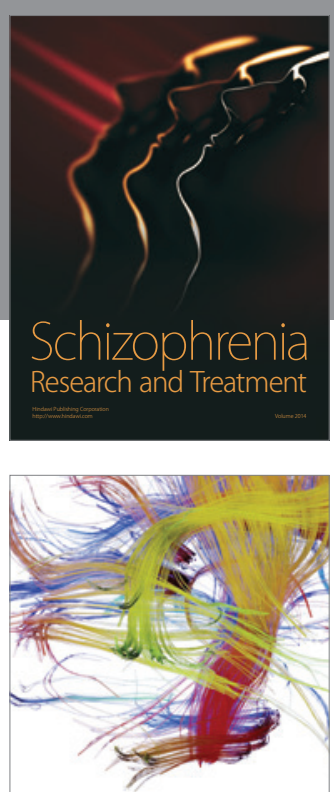

Brain Science

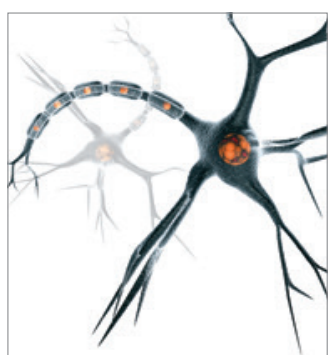

Neural Plasticity
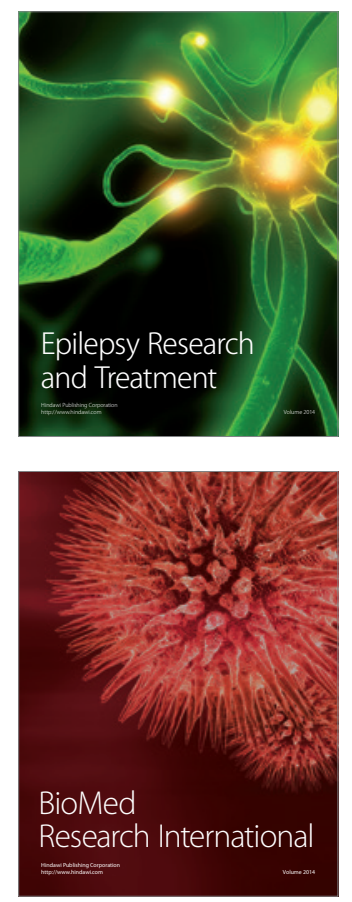

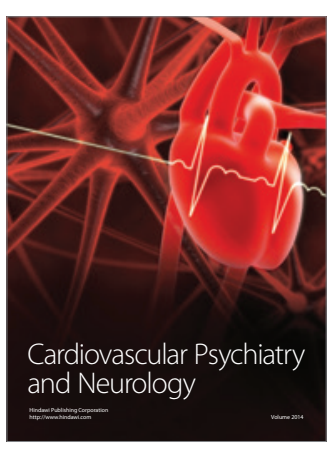

Parkinson's

Disease
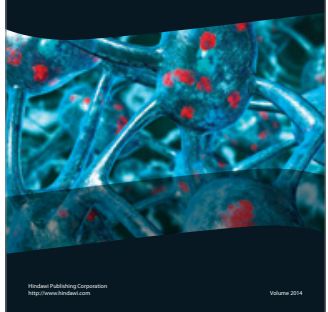